Article

\title{
Investigation of Hydrogen Content and Dilution Effect on Syngas/Air Premixed Turbulent Flame Using OH Planar Laser-Induced Fluorescence
}

\author{
Li Yang ${ }^{1,2, *(\mathbb{D})}$, Wubin Weng ${ }^{3}\left(\mathbb{D}\right.$, Yanqun Zhu ${ }^{4}$, Yong $\mathrm{He}^{4}$, Zhihua Wang ${ }^{4}$ and Zhongshan Li $^{3}(\mathbb{D})$ \\ 1 Key Laboratory for Technology in Rural Water Management of Zhejiang Province, Zhejiang University of \\ Water Resources and Electric Power, Hangzhou 310018, China \\ 2 College of Electrical Engineering, Zhejiang University of Water Resources and Electric Power, \\ Hangzhou 310018, China \\ 3 Division of Combustion Physics, Lund University, P.O. Box 118, S-22100 Lund, Sweden; \\ wubin.weng@forbrf.lth.se (W.W.); zhongshan.li@forbrf.lth.se (Z.L.) \\ 4 State Key Laboratory of Clean Energy Utilization, Zhejiang University, Hangzhou 310012, China; \\ yqzhu@zju.edu.cn (Y.Z.); heyong@zju.edu.cn (Y.H.); wangzh@zju.edu.cn (Z.W.) \\ * Correspondence: yangl@zjweu.edu.cn
}

Citation: Yang, L.; Weng, W.; Zhu, Y.; $\mathrm{He}, \mathrm{Y}$; Wang, Z.; Li, Z. Investigation of Hydrogen Content and Dilution Effect on Syngas/Air Premixed Turbulent Flame Using OH Planar Laser-Induced Fluorescence. Processes 2021, 9, 1894. https://doi.org/ $10.3390 / \mathrm{pr} 9111894$

Academic Editor: Adam Smoliński

Received: 6 October 2021

Accepted: 20 October 2021

Published: 23 October 2021

Publisher's Note: MDPI stays neutral with regard to jurisdictional claims in published maps and institutional affiliations.

Copyright: (c) 2021 by the authors. Licensee MDPI, Basel, Switzerland. This article is an open access article distributed under the terms and conditions of the Creative Commons Attribution (CC BY) license (https:// creativecommons.org/licenses/by/ $4.0 /)$.

\begin{abstract}
Syngas produced by gasification, which contains a high hydrogen content, has significant potential. The variation in the hydrogen content and dilution combustion are effective means to improve the steady combustion of syngas and reduce $\mathrm{NO}_{\mathrm{x}}$ emissions. $\mathrm{OH}$ planar laser-induced fluorescence technology (OH-PLIF) was applied in the present investigation of the turbulence of a premixed flame of syngas with varied compositions of $\mathrm{H}_{2} / \mathrm{CO}$. The flame front structure and turbulent flame velocities of syngas with varied compositions and turbulent intensities were analyzed and calculated. Results showed that the trend in the turbulent flame speed with different hydrogen proportions and dilutions was similar to that of the laminar flame speed of the corresponding syngas. A higher hydrogen proportion induced a higher turbulent flame speed, higher $\mathrm{OH}$ concentration, and a smaller flame. Dilution had the opposite effect. Increasing the Reynolds number also increased the turbulent flame speed and $\mathrm{OH}$ concentration. In addition, the effect of the turbulence on the combustion of syngas was independent of the composition of syngas after the analysis of the ratio between the turbulent flame speed and the corresponding laminar flame speed, for the turbulent flames under low turbulent intensity. These research results provide a theoretical basis for the practical application of syngas with a complex composition in gas turbine power generation.
\end{abstract}

Keywords: dilution; hydrogen content; turbulent flame; premixed; $\mathrm{OH}$; planar laser-induced fluorescence

\section{Introduction}

Syngas, which is mainly composed of hydrogen and CO, is considered a form of potential fuel and has wide application prospects in gas turbine power generation. However, like all other fossil fuels, syngas emits pollutants such as $\mathrm{NO}_{\mathrm{x}}$ as it burns. Diluting the combustion mixture is a general method to control $\mathrm{NO}_{\mathrm{x}}$ emissions [1-3], especially with high temperature diluents to create a distributed reaction zone and mild combustion [2]. Gas diluents, which normally denote incombustible gas, including $\mathrm{N}_{2}, \mathrm{CO}_{2}, \mathrm{H}_{2} \mathrm{O}$, and exhaust gas re-circulation (EGR) [4], can significantly reduce the chemical reaction rate and temperature of the reaction zone, and thus decrease the formation of $\mathrm{NO}_{\mathrm{x}}$. The utilization of low calorific value (LCV) gas fuels, including a massive amount of incombustible gas, such as syngas, is a typical dilution combustion. It is of great significance to study the effect of dilution on the combustion characteristics of syngas in future applications.

Mixing hydrogen with hydrocarbon fuels can significantly reduce carbon emissions. Premixed, lean-burn is an effective combustion method to reduce the emission of nitrogen 
oxide [5]. The premixed dilution combustion of hydrogen-blended fuel is also an important method to improve efficiency and reduce emissions of gas turbine [6].

Laser diagnostic technologies, including planar laser-induced fluorescence (PLIF) and Rayleigh scattering (RS), are widely used in the research of combustion. PLIF technology is used widely, especially for turbulent combustion, and much essential information of flames can be obtained, such as the structure of the turbulent flame [7,8], OH radical laser measurement [9,10], and other intermediate free radical products [11]. Zhang et al. [12] investigated the turbulent premixed flame structure characteristics of hydrogen-enriched methane/air flames diluted with $\mathrm{CO}_{2}$ using OH-PLIF and revealed the role of hydrogen addition and $\mathrm{CO}_{2}$ dilution on the features of the turbulent flame. Zhang et al. [4] pointed out that both $\mathrm{CO}_{2}$ and $\mathrm{H}_{2} \mathrm{O}$ diluents have a certain effect on inhibiting the $\mathrm{NO}$ generation of $\mathrm{CH}_{4}$ /air premixed flame by OH-PLIF and Fluent in combination with the simplified mechanism. Zhang et al. [13] studied the influence of hydrogen addition on the detailed flame structure of turbulent premixed flame of $\mathrm{CH}_{4} / \mathrm{H}_{2}$ /air mixture using $\mathrm{CH}_{2} \mathrm{O} / \mathrm{OH}$ PLIF and revealed that hydrogen broadens the reaction zone slightly but largely decreases the preheat zone thickness.

The effect of $\mathrm{N}_{2}$ dilution and hydrogen content on the combustion characteristics of the syngas/air premixed turbulent flame with different dilution ratios and different exit Reynolds numbers was examined in the present work. The distribution of free radical $\mathrm{OH}$ in the jet flame was measured by PLIF, which was mainly used to obtain the structure of the flame front and to extract the turbulent flame velocity [2]. Different fuels were studied, which mainly consisted of a mixture of hydrogen and carbon monoxide in different proportions. The ratio of hydrogen to carbon monoxide varied from $5 / 95$ to $75 / 25$, which represented different types of syngas. In order to determine the effect of a high degree of dilution on the premixed turbulent flame, the proportion of dilution gas used in the experiment was up to $50 \%$, which was higher than that used in other literature $[2,3,14,15]$.

\section{Experiment Methods}

\subsection{Experiment Setup}

The experiment setup employed in the present work is shown in Figure 1, including the combustion system and laser diagnostic system. The combustion system is comprised of a water-cooled McKenna burner with a center jet tube, and several mass flow controllers (Alicat) to provide a precise supply of gas. The center jet tube was surrounded by a co-flow comprised of hot flue gas which was generated from a laminar premixed flame of methane/air $(\varphi=0.9)$ located about $2 \mathrm{~mm}$ below the jet tube exit, and the exit was $4 \mathrm{~mm}$ above the surface of the McKenna burner. In the present work for syngas, the inner diameter of the center jet tube was $2.3 \mathrm{~mm}$, which was slightly different from our previous work for methane [16].

The jet flow conditions of syngas/air premixed jet flame used in the present experiment are shown in Table 1 . The equivalence ratio was maintained at 0.9 . The volumetric ratio of gaseous hydrogen to carbon monoxide varied from $5 / 95$ to $75 / 25$, which represented different types of syngas. Air was emulated with $21 \mathrm{v} \% \mathrm{O}_{2}$ and $79 \mathrm{v} \% \mathrm{~N}_{2}$, and the proportion of dilution gas varied from 0 to $50 \mathrm{v} \%$, in order to determine the effect of high dilution on the premixed turbulent flame. The dilution ratio is equal to the volume of dilute gas divided by the total volume of gas mixture. For each of the operation conditions, velocities of $40 \mathrm{~m} / \mathrm{s}(\operatorname{Re}=6110), 70 \mathrm{~m} / \mathrm{s}(\operatorname{Re}=10,690)$, and $100 \mathrm{~m} / \mathrm{s}(\operatorname{Re}=15,270)$ at the jet exit were selected to achieve different Reynolds numbers.

The PLIF system was adopted for $\mathrm{OH}$ measurement. A frequency-double Quanta-Ray Nd:YAG laser (PRO-250-10H, Spectra physics, Santa Clara, CA, USA) was used to produce a $10 \mathrm{~Hz}$ pulse laser with a single pulse energy of $1500 \mathrm{~mJ}$. The laser pulse width was about 10 nanoseconds. At the same time, the laser can generate pulses of 532, 355, or 266 nanometers using the double frequency crystal, triple frequency crystal or quadruple frequency crystal, respectively, carried by the laser itself. In the present experimental system, the Nd:YAG laser with a 532 nanometer pulse was used to pump a dye laser (ND6000, 
Continuum, Boston, MA, USA) to generate a $283.049 \mathrm{~nm}$ UV laser (with a pulse energy of $15 \mathrm{~mJ}$ ) with a frequency doubler. This UV laser was transformed into a vertical laser sheet with a length of $32 \mathrm{~mm}$ (the thickness of laser sheet was very thin) using a spherical convex lens $(\mathrm{f}=+300 \mathrm{~mm})$ and a cylindrical concave lens $(\mathrm{f}=-30 \mathrm{~mm})$, passing vertically through the center of the flame to excite the Q1(8) line of $\mathrm{OH}$ with the transition of $\mathrm{A}^{2} \Sigma \leftarrow X^{2} \Pi(1,0)$. The corresponding fluorescence was captured by an intensified charge coupled device (ICCD) camera (PI MAX 3, Princeton Instruments, Trenton, NJ, USA) with a $1024 \times 1024$ pixel array. A UV lens (105 mm focal length, Nikon, Tokyo, Japan) and two combined Schott filters (WG305 and UG11) were used to obtain the fluorescence signal around $308 \mathrm{~nm}$. The spectra of the laser-induced fluorescence was analyzed using a monochromator (SP2358, Acton-type spectrometer, Princeton Instrument).

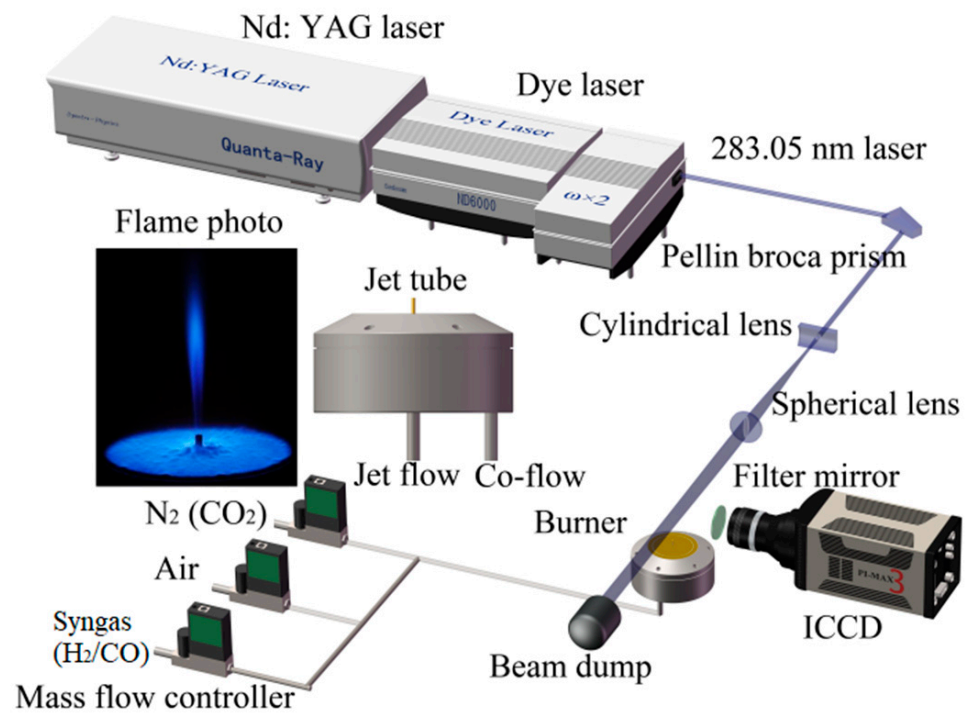

Figure 1. Schematic of experiment setup.

Table 1. Operation conditions of syngas/air premixed jet flame.

\begin{tabular}{ccc}
\hline $\mathbf{H}_{\mathbf{2}}: \mathbf{C O}(\boldsymbol{v} / \boldsymbol{v})$ & $\begin{array}{c}\text { Proportion of } \mathbf{N}_{\mathbf{2}} \text { Dilution } \\
\mathbf{( v \% )}\end{array}$ & Velocity at the Jet Exit \\
\hline $5: 95$ & $0,10,30,50$ & For each of the above conditions, \\
$25: 75$ & $0,10,30,50$ & $40 \mathrm{~m} / \mathrm{s}(\mathrm{Re}=6110), 70 \mathrm{~m} / \mathrm{s}$ \\
$50: 50$ & $0,10,30,50$ & $(\operatorname{Re}=10,690)$ and $100 \mathrm{~m} / \mathrm{s}$ \\
$75: 25$ & $0,10,30,50$ & $(\operatorname{Re}=15,270)$ were selected \\
\hline
\end{tabular}

\subsection{Data Process}

The area of the flame front surface, the average area of the flame surface, the wrinkled rate of the flame surface, and the rate of the unburned premixed gas consumption per average flame front area, the so-called turbulent flame velocity, were analyzed in the present experiment in the wrinkled and corrugated regions. In Figure 2, the laminar flame velocity in (a) can be expressed as $\mathrm{SL}=\mathrm{U} 0=\mathrm{Q} / \mathrm{AL}$, where $\mathrm{AL}$ represents the area of the front of the laminar premixed flame and AT represents the area of the corrugated front of the turbulent premixed flame. $\mathrm{U} 0$ is the inlet velocity. The solid lines represent the front surface and the dashed lines represent the average front surface. $Q$ is the outlet flow of unburned gas. Thus, the laminar flame velocity can be understood as the volume consumption rate of unburned premixed gas per unit flame front surface. For turbulent flames with wrinkling, this parameter can also be extracted using the same method. The volume consumption rate of unburned premixed gas or the turbulent flame velocity per unit flame front surface can be expressed as $\mathrm{S}_{\mathrm{T}}=\mathrm{U}_{0}=\mathrm{S}_{\mathrm{L}} \times \mathrm{A}_{\mathrm{T}} / \mathrm{A}_{\mathrm{avg}}=\mathrm{Q} / \mathrm{A}_{\mathrm{avg}}$. $\mathrm{A}_{\mathrm{avg}}$ represents the average front area of turbulent flame, which is indicated by a dotted line 
in (b)(d). For the Bunsen burner flame in (c), $S_{L}=U_{0} \times A_{0} / A_{L}$, where $A_{0}$ represents the exit area of the Bunsen burner. Different syngas jet flames can be processed as the Bunsen burner flame, as shown in Figure 2d.

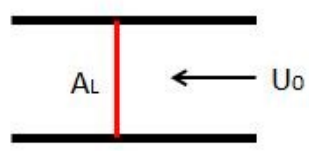

(a)

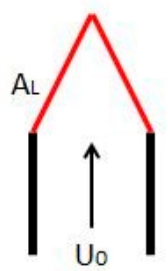

(c)

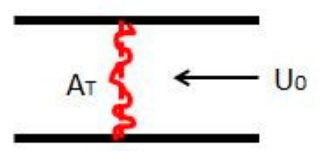

(b)

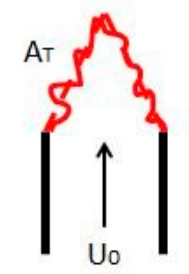

(d)

Figure 2. Flame front surface of $(\mathbf{a}, \mathbf{c})$ laminar premixed flame and $(\mathbf{b}, \mathbf{d})$ turbulent premixed flame.

The premixed turbulent jet flames have low turbulent intensity, and they are wrinkled flames and corrugated flames, which were generated with different Reynolds number by a flat flame burner which contains a center jet tube. The single shot of the OH-PLIF image clearly presents the structure of the flame front. These images were used in the present study to calculate the turbulent flame speed of the syngas with varied compositions and turbulent intensities. The corresponding turbulent flame velocities were obtained by processing the OH-PLIF images of different syngas jet flames. The whole data process is shown in Figure 3. The color bar with the value from 0 to 2000 represents the signal intensity of the $\mathrm{OH}$ radical: the larger the color number, the stronger the signal intensity. All of the color bars with values in the following figures represent the signal intensity of $\mathrm{OH}$ radical. Figure 3a represents a typical OH-PLIF instantaneous image of a jet flame. The unburned area and the burned area can be distinguished according to the intensity of the $\mathrm{OH}$ fluorescence signal. During the image processing, the unburned region was assigned to 0 and the burned region was assigned to 1 , as shown in Figure $3 \mathrm{~b}$. The flame is shown as black for the unburned region, assigned 0 , white for the burned region, and assigned 1. In the present experiment, 500 instantaneous images were collected for each operation condition. The unburned area and the burned area were treated with the binary method, and 500 average images (Figure 3c) were obtained, which showed the probability distributions of the unburned and burned regions. The isolines with a value of 0.5 were extracted from Figure $3 c$ to obtain the average flame front of the turbulent flame. The contours of isolines with a value of 0.5 and the corresponding fitting lines are shown in Figure $3 \mathrm{~d}$ because of the symmetry of the flame. The average front surface area of turbulent flame was obtained by rotating the integral of the fitted line, and then the turbulent flame velocity was calculated by the following formula:

$$
S_{T}=U_{0} \times A_{0} / A_{T}
$$

where $S_{T}$ represents the turbulent flame velocity, $U_{0}$ represents the jet exit velocity, $A_{0}$ represents the jet exit area, and $A_{\mathrm{T}}$ represents the average front surface area of the turbulent flame.

Figure 4a presents a typical OH-PLIF instantaneous flame image of an operation condition. The instantaneous front surface structure of the flame can be extracted from the OH-PLIF instantaneous flame image (Figure 4a), and the flame front (Figure $4 \mathrm{~b}$ ) can be achieved distinctly with the adaptive threshold method. First, the background signal was subtracted and the effect of the uneven distribution of laser energy was removed from the original image using MATLAB. Second, the spot was assigned to 1 when the intensity of the $\mathrm{OH}$ fluorescence signal was more than 0 , or the spot was assigned to 0 . 
Therefore, a black and white picture could be obtained and the burned region was white and the unburned region was black. In the present experiment, 500 transient images were collected for each case. Overlaying of the flame front boundaries (Figure 4c) was obtained by superposing 500 fronts, which can be used in statistical analysis with averaging and root mean square (RMS) values to obtain the analysis of the distribution of the fronts and other important information.

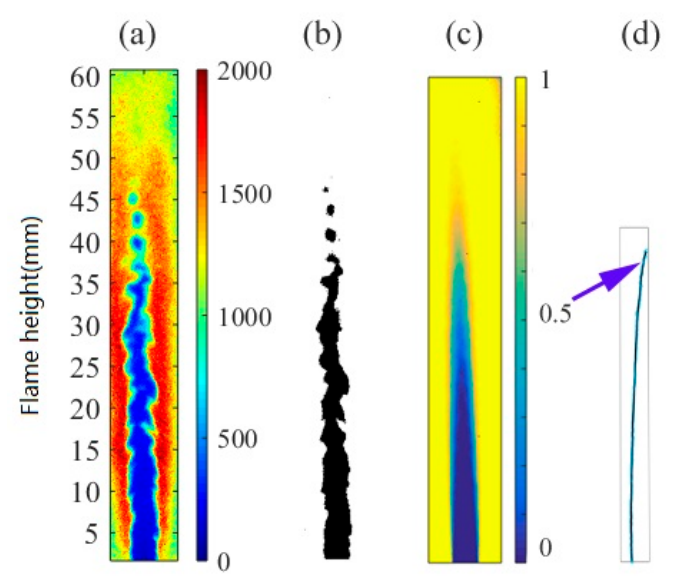

Figure 3. Data process and calculation of the turbulent flame speed: (a) flame instantaneous image of typical OH-PLIF; (b) flame instantaneous image of unburned and burned areas; (c) probability distribution images of unburned and burned areas; (d) contour lines of value 0.5 and corresponding fitting lines (extracted from Figure 2c).

(a)

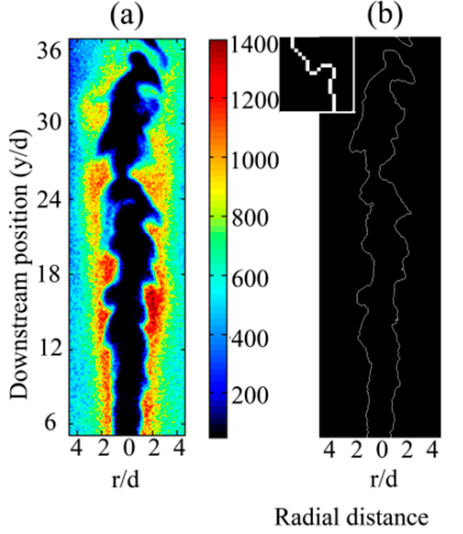

(c)

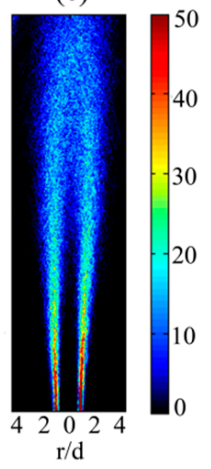

Figure 4. Analysis process of flame front surface: (a) instantaneous image of OH-PLIF; (b) flame front of the instantaneous image; (c) overlaying of 500 flame front boundaries.

Additionally, the wrinkle ratio of flames was also calculated according to those flame front boundaries. The wrinkle ratio is a significant parameter to demonstrate the scale of the turbulent flame front fractality. The bigger the wrinkle ratio, the stronger the turbulent intensity, and the more flame front fractality. The wrinkle ratio of flames is equal to the flame front length divided by the given flame height at the vertical distance, which was determined as $1 \mathrm{~mm}$ in the current experiment. The flame front length is the length within a given flame height at a given downstream position. The distance between two neighboring pixels with corner connection was counted as the square root of two times that of the number of pixels with a side connection, as shown in Figure $4 b$.

\section{Results and Discussions}

In the present work, the premixed jet flame of a syngas/air mixture with different nitrogen dilutions was investigated. The volumetric ratio of hydrogen to carbon monoxide varied from $5 / 95,25 / 75$, and $50 / 50$ to $75 / 25$, which represented different types of syn- 
gas. The volumetric proportion of dilution gas varied from $0,10 \%$, and $30 \%$ to $50 \%$ to determine the effect of high dilution on the premixed turbulent flame. The turbulent flame velocities under different operating conditions were calculated and analyzed at different Reynolds numbers.

Figures 5-8 show the instantaneous $\mathrm{OH}$ distributions of different volumetric ratios of $5 \% \mathrm{H}_{2}-95 \% \mathrm{CO}, 25 \% \mathrm{H}_{2}-75 \% \mathrm{CO}, 50 \% \mathrm{H}_{2}-50 \% \mathrm{CO}$, and $75 \% \mathrm{H}_{2}-25 \% \mathrm{CO}$ with different dilutions and Reynolds number at different outlets. As can be seen from these figures, the common point was that increasing the nitrogen dilution proportion greatly reduced the concentration of the $\mathrm{OH}$ radical, increased the flame height, and increased the vortex size of the flame. In our previous work, we studied the effects of nitrogen and carbon dioxide dilution on the combustion of gaseous fuels, such as methane [16] and syngas [17]. The effect of nitrogen and carbon dioxide dilution on methane combustion was investigated by formaldehyde-PLIF and OH-PLIF. The dilution resulted in the delay of combustion, the expansion of the unburned zone, and the significant decrease in the concentration of formaldehyde and $\mathrm{OH}$. Compared with the super lean combustion, the dilution combustion more obviously weakened the combustion. Moreover, compared with nitrogen dilution, the $\mathrm{OH}$ concentration in the combustion zone was reduced more obviously by carbon dioxide dilution, but the formation of formaldehyde in the unburned zone was not affected.

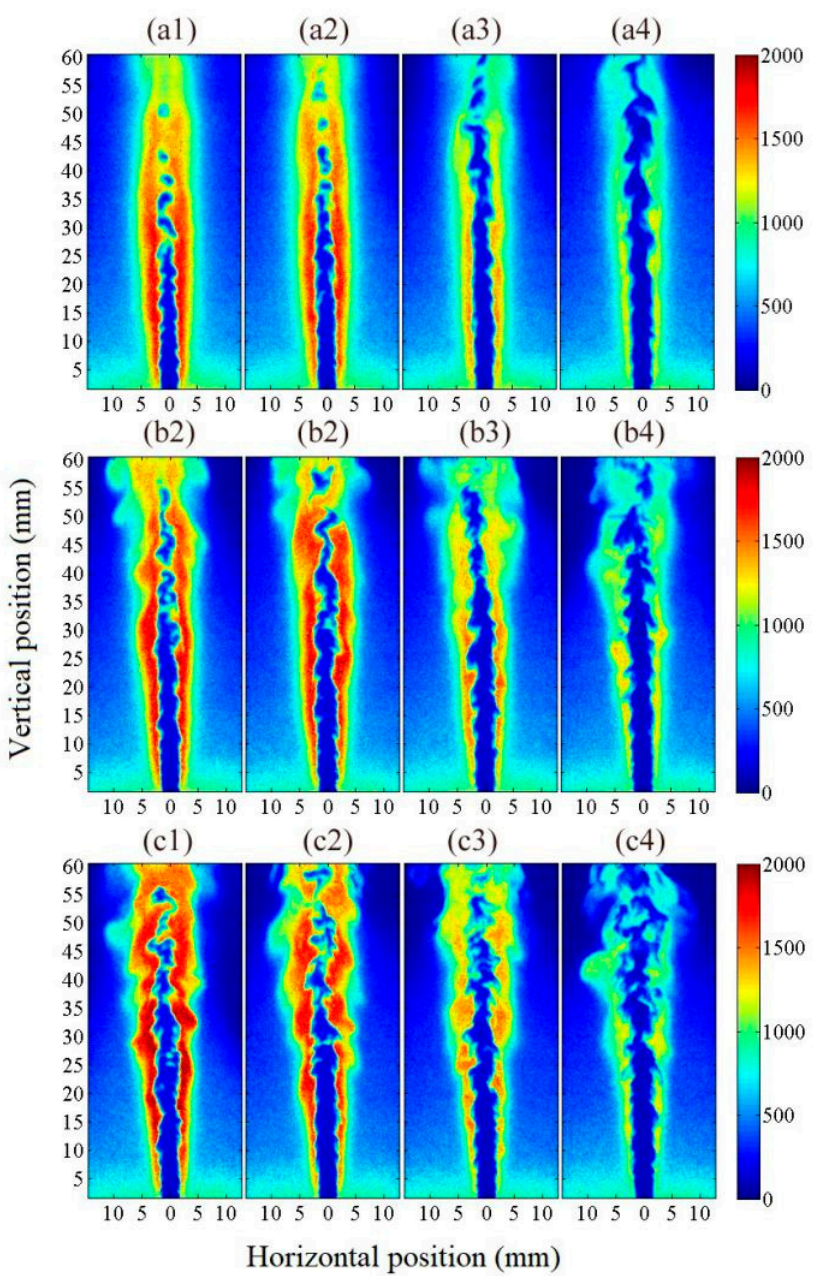

Figure 5. $\mathrm{OH}$ distribution instantaneous image of syngas with volumetric ratio of $5 \% \mathrm{H}_{2}-95 \% \mathrm{CO}$ under different dilutions and Reynolds numbers: (a1-a4) $\operatorname{Re}=6110 ;(\mathbf{b 1}-\mathbf{b 4}) \operatorname{Re}=10,690$; (c1-c4) $\operatorname{Re}=15,270.1,2,3$, and 4 indicate nitrogen dilution volumetric proportions of $0 \%, 10 \%$, $30 \%$, and $50 \%$, respectively. 
(a1)

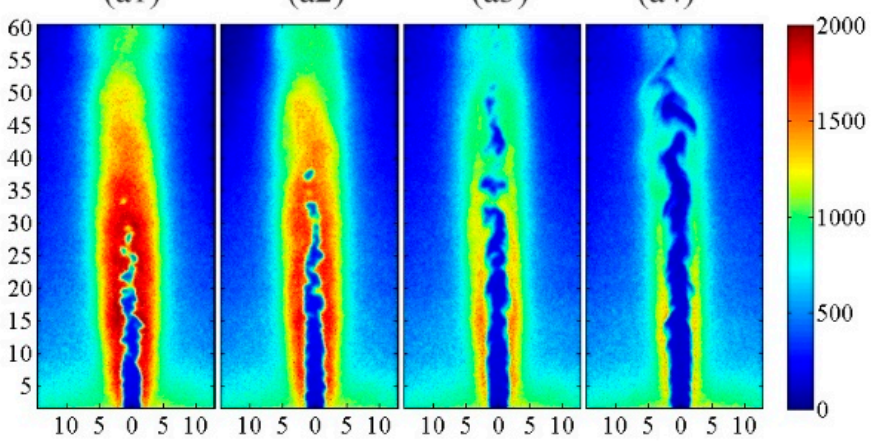

(b1)

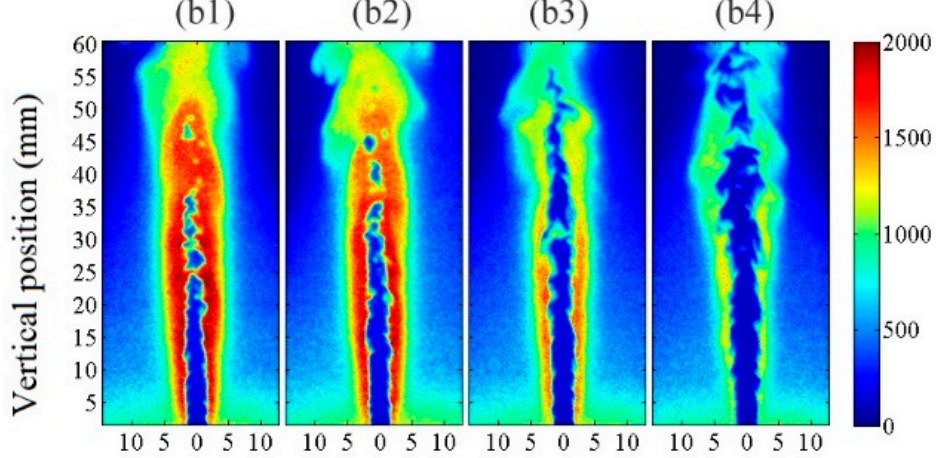

(c1)

(c2)

(c3)

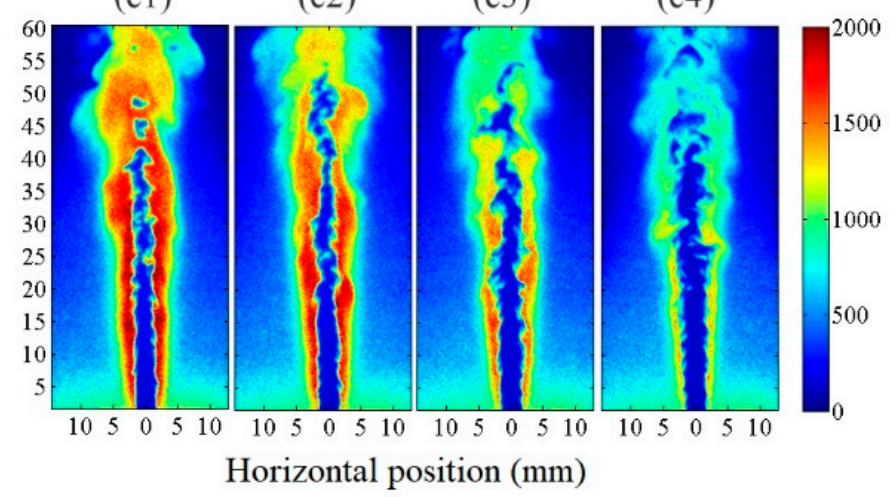

Figure 6. $\mathrm{OH}$ distribution instantaneous image of syngas with volumetric ratio of $25 \% \mathrm{H}_{2}-$ 75\%CO under different dilutions and Reynolds numbers: (a1-a4) $\operatorname{Re}=6110$; (b1-b4) $\operatorname{Re}=10,690$; (c1-c4) $\operatorname{Re}=15,270.1,2,3$, and 4 indicate nitrogen dilution volumetric proportions of $0 \%, 10 \%, 30 \%$, and $50 \%$, respectively.

The increase in the hydrogen content in the syngas increased the concentration of $\mathrm{OH}$ to a certain extent, and greatly reduced the size of the flame surface. These changes were greatly affected by the variation of laminar flame velocity characteristics of the premixed syngas, which was consistent with the results discussed in the previous work [18]. In addition, changing the Reynolds number of the jet exit had very similar effects for different fuels. Increasing the exit Reynolds number enhanced the concentration distribution of $\mathrm{OH}$ signal, increasing the flame height and the vortex structure of the flame front.

Figure 9 shows the length of the wrinkled flame front under different flame conditions. The results show that the total length of the flame front increased as the hydrogen proportion in the fuel decreased and the nitrogen dilution increased. This was mainly affected by the laminar flame velocity of the fuel. A smaller laminar flame velocity resulted in a larger flame front to sustain constant combustion under the condition of the same exit velocity. In addition, the total length of the flame front increased with the increase in turbulence intensity. 
(a1)

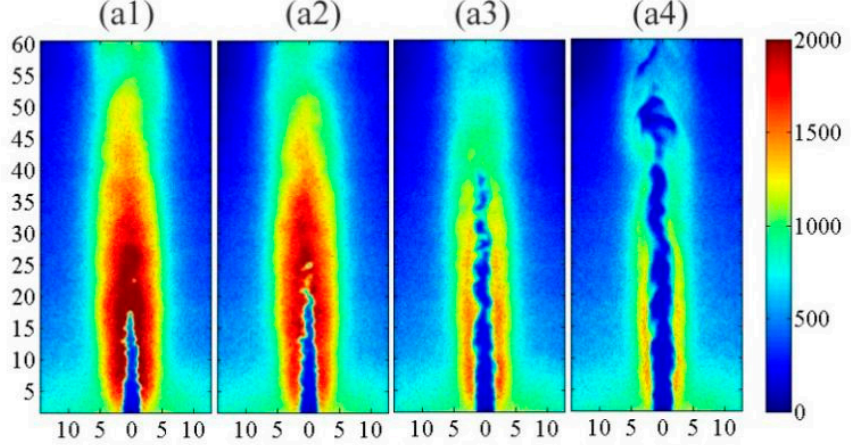

(b1)

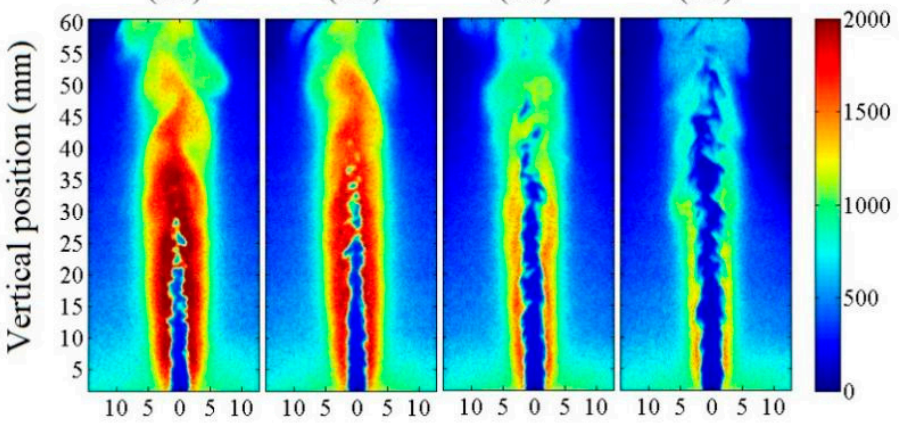

(c1)

(c2)

(c3)

(c4)

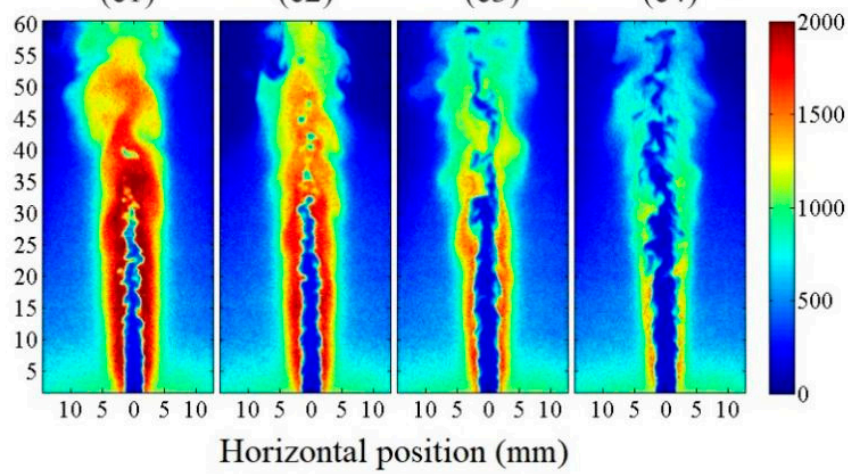

Figure 7. $\mathrm{OH}$ distribution instantaneous image of syngas with volumetric ratio of $50 \% \mathrm{H}_{2}-$ 50\%CO under different dilutions and Reynolds numbers: (a1-a4) $\operatorname{Re}=6110$; (b1-b4) $\operatorname{Re}=10,690$; (c1-c4) $\operatorname{Re}=15,270.1,2,3$, and 4 indicate nitrogen dilution volumetric proportion of $0 \%, 10 \%, 30 \%$, and $50 \%$, respectively.

In order to obtain the effect of turbulence on combustion, the average flame front length and the total length of the wrinkled flame front are normalized in Figure 10 to obtain the wrinkled rate of the flame front surface. It can be seen that the trend of the wrinkled rate was consistent with that of the total length of the wrinkled flame front in Figure 9. Firstly, the wrinkled rate of flame front increased as the exit Reynolds number increased. Secondly, more abundant flame wrinkles were present in the turbulent combustion for the fuel with a lower laminar flame velocity. The increase in the wrinkle rate was mainly due to the increase in the higher wrinkle rate area caused by the expansion of the flame volume. 

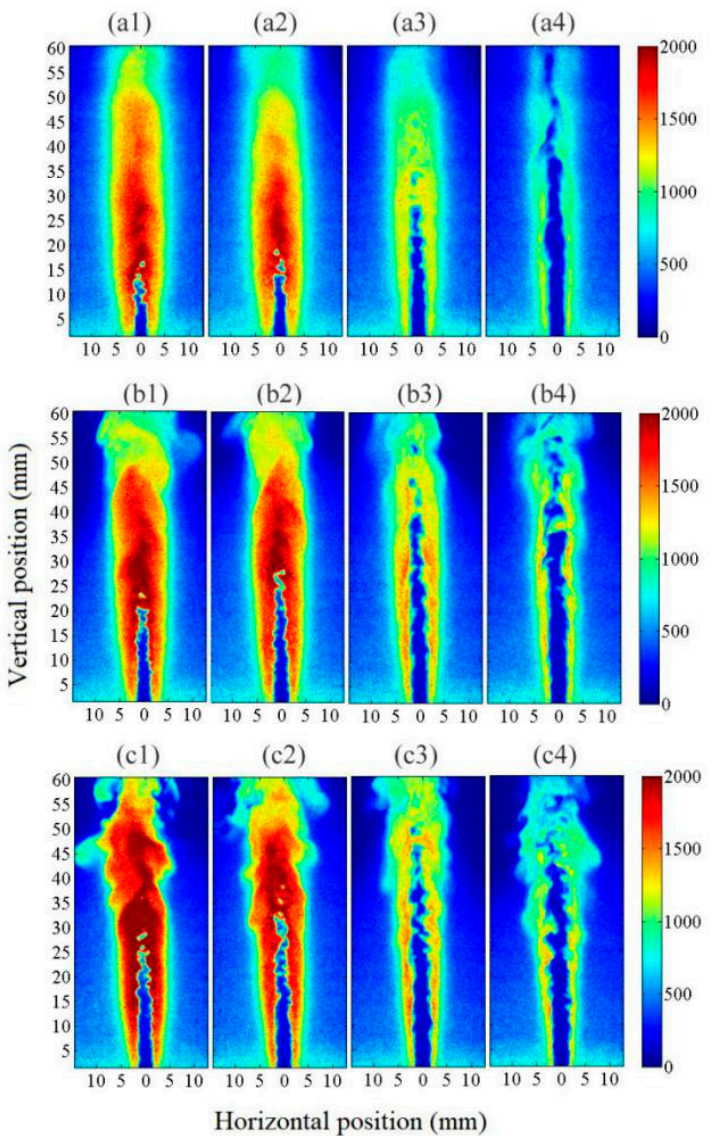

Figure 8. $\mathrm{OH}$ distribution instantaneous image of syngas with volumetric ratio of $75 \% \mathrm{H}_{2}-$ 25\%CO under different dilutions and Reynolds numbers: (a1-a4) $\operatorname{Re}=6110$; (b1-b4) $\operatorname{Re}=10,690$; (c1-c4) $\operatorname{Re}=15,270.1,2,3$, and 4 indicate nitrogen dilution volumetric proportion of $0 \%, 10 \%, 30 \%$, and $50 \%$, respectively.
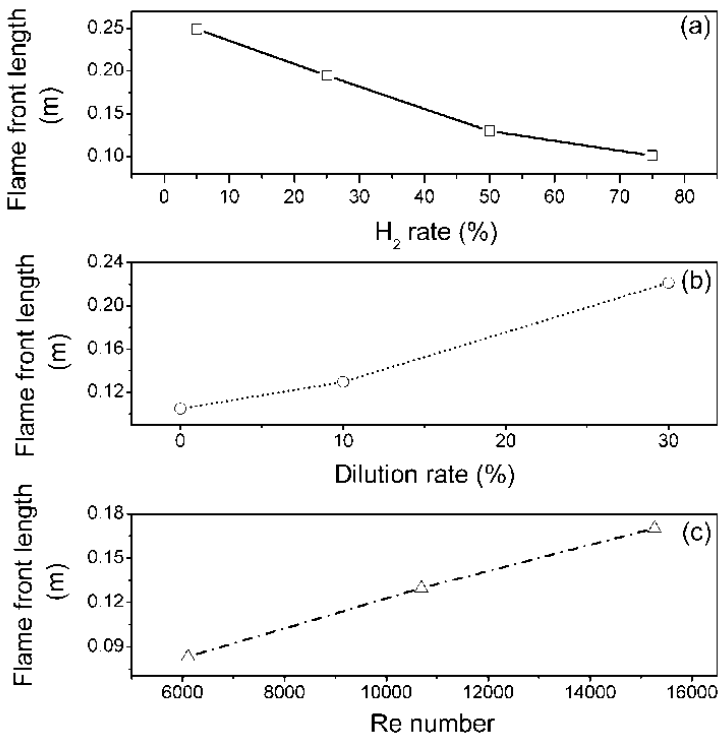

Figure 9. Length of wrinkled flame front under different flame conditions: (a) nitrogen dilution volumetric proportion of $10 \%, \operatorname{Re}=10,690$, different hydrogen proportion in fuel; (b) hydrogen volumetric rate of $50 \%, \operatorname{Re}=10,690$, different nitrogen dilution; (c) nitrogen dilution volumetric proportion of $10 \%$, hydrogen volumetric ratio of $50 \%$, different Reynolds number. 

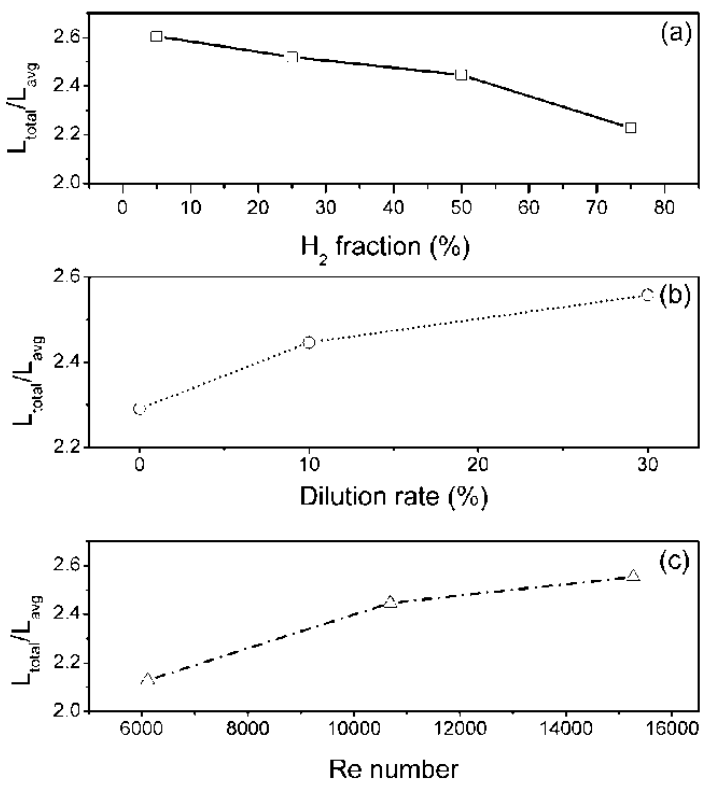

Figure 10. Wrinkled rate under different flame conditions: (a) nitrogen dilution volumetric proportion of $10 \%, \operatorname{Re}=10,690$, different hydrogen proportion in fuel; (b) hydrogen volumetric rate of $50 \%, \operatorname{Re}$ $=10,690$, different nitrogen dilution; (c) nitrogen dilution volumetric proportion of $10 \%$, hydrogen volumetric ratio of $50 \%$, different Reynolds number.

In order to understand the variation in the flame wrinkled rate at different flame positions under different flame conditions, Figures 11 and 12 show the wrinkled rates at different flame heights with different hydrogen contents and Reynolds numbers at different outlets. Under different working conditions, the maximum wrinkled rate does not change much. The increase in the wrinkled rate in Figure 10 is mainly due to the increase in the area with the high wrinkled rate caused by the change in the flame volume.

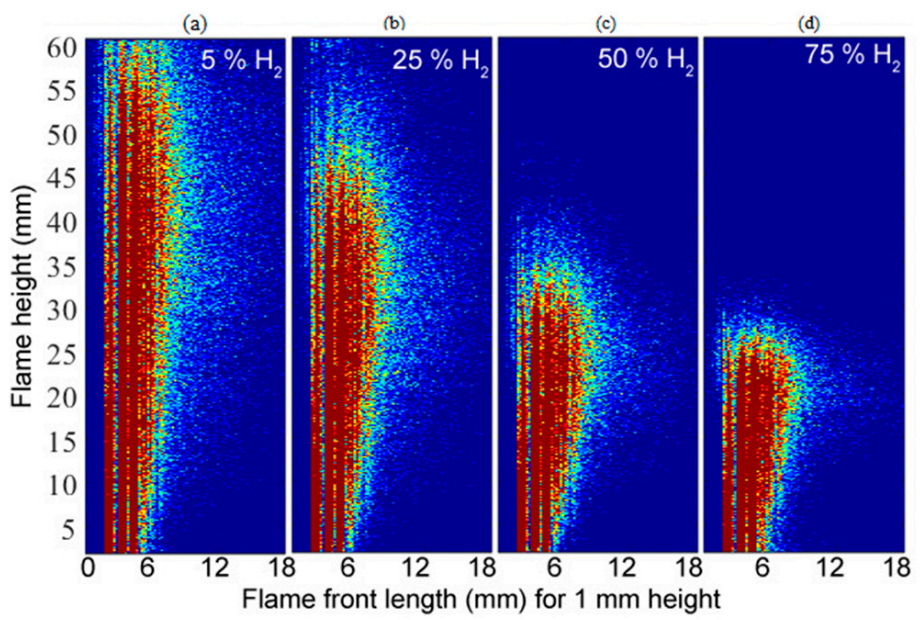

Figure 11. Wrinkled rate under different flame heights with nitrogen dilution volumetric proportion of $10 \%, \operatorname{Re}=10,690$, different hydrogen proportion in fuel: (a) hydrogen volumetric rate of $5 \%$; (b) $25 \%$; (c) $50 \%$; (d) $75 \%$. 


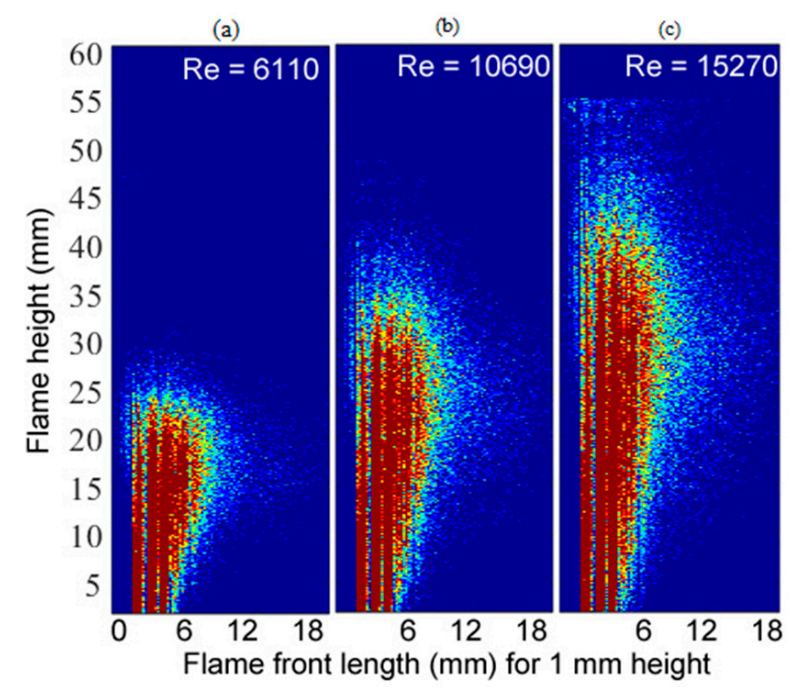

Figure 12. Wrinkled rate under different flame heights with nitrogen dilution volumetric proportion of $10 \%$, hydrogen proportion of 50\%, different Reynolds number: (a) $\operatorname{Re}=6110$; (b) $\operatorname{Re}=10,690$; (c) $\operatorname{Re}=15,270$.

In the present work, the maximum exit velocity of turbulent jet flow was $100 \mathrm{~m} / \mathrm{s}$. It should be noted that the exit velocity of the turbulent jet flow was different from the turbulent flame velocity/speed. The exit velocity of the turbulent jet flow indicates the flow velocity of unburned premixed fuel gases and is closely related to the Reynolds number (jet flow exit velocity of $100 \mathrm{~m} / \mathrm{s}$ corresponds to Reynolds number of 15,270, as shown in Table 1), whereas the turbulent flame velocity denotes the turbulent flame propagation speed. Based on the previous studies [19], the turbulence intensity was estimated to be about $1 \%$ of the exit velocity of the jet flow. Therefore, the turbulence intensity at the front of the present experimental flame was about $100 \mathrm{~cm} / \mathrm{s}$. The laminar flame velocity of the syngas used in the present experiment was about $100 \mathrm{~cm} / \mathrm{s}$. Thus, it was estimated that the turbulent premixed jet flame in the present experiment basically lies in the wrinkled and corrugated flamelets. In these wrinkled and corrugated regions, the area of the flame front surface, the average area of the flame surface, the wrinkled rate of the flame surface, and the rate of unburned premixed gas consumption per average flame front area-the so-called turbulent flame velocity-were analyzed.

Figure 13 shows the tendency of the turbulent flame velocity to vary with the proportion of hydrogen in syngas. Compared with the laminar flame velocity obtained by CHEMKIN simulation, the turbulent and laminar flame velocities had a very similar changing trend. It can be seen that the turbulent flame velocity was basically controlled by the laminar flame velocity under invariable turbulent intensity.

In order to study the effect of the exit velocity on turbulent flame velocity, the ratio of the turbulent flame velocity to the laminar flame velocity of syngas with the same composition was obtained, as shown in Figure 14.

As can be seen from Figure 14, the ratio of turbulent flame velocity to laminar flame velocity decreased significantly with the increase in hydrogen content in syngas under invariable turbulent intensity. For different operation conditions of syngas, the increase in turbulent flame velocity was consistent with the increase in exit Reynolds number, as shown in Figure 13. Therefore, the increase in laminar flame velocity directly resulted in the decrease in the ratio of turbulent flame velocity to laminar flame velocity. 


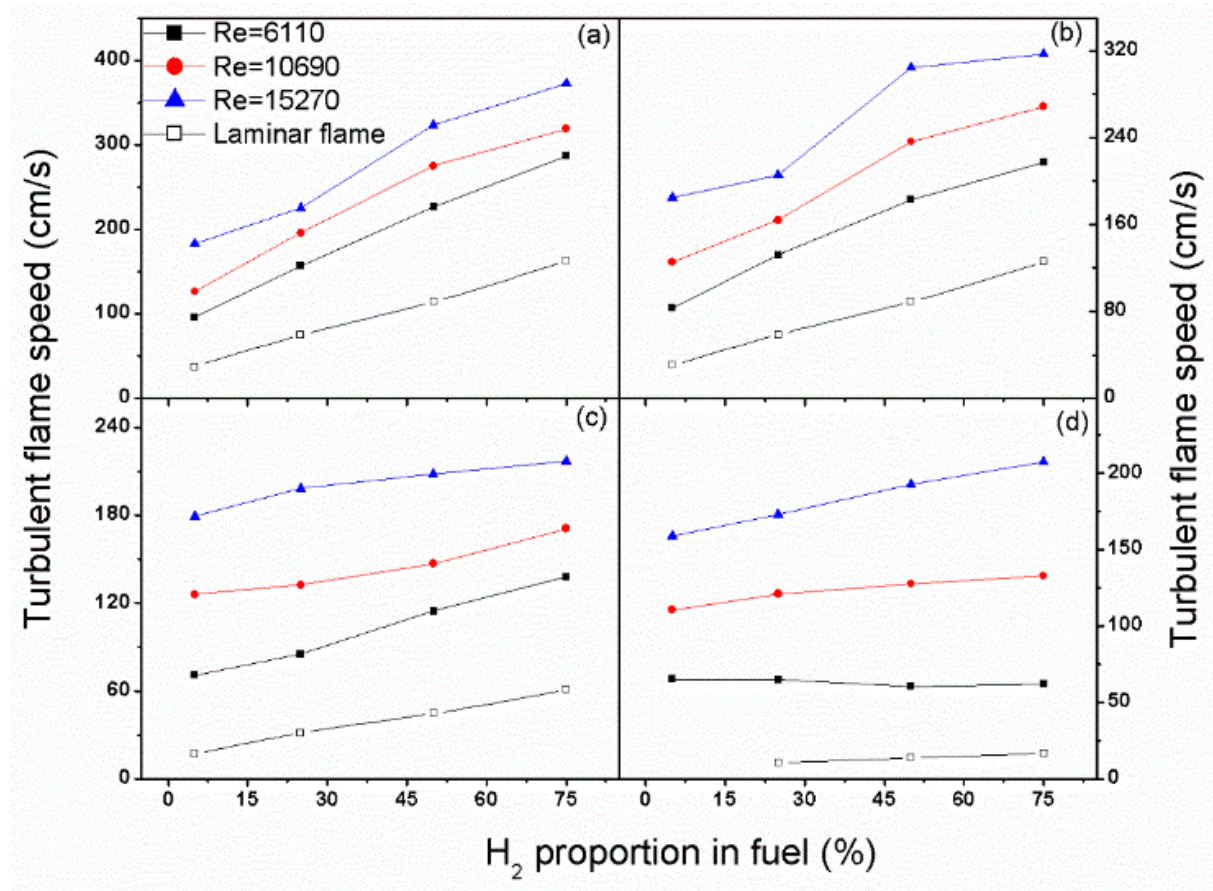

Figure 13. Trend of the turbulent flame velocity of syngas with different nitrogen dilution rates, under different hydrogen proportions in fuel and exit Reynolds numbers: (a) $0 \%$; (b) $10 \%$; (c) $30 \%$; (d) $50 \%$ nitrogen dilution volumetric rate.

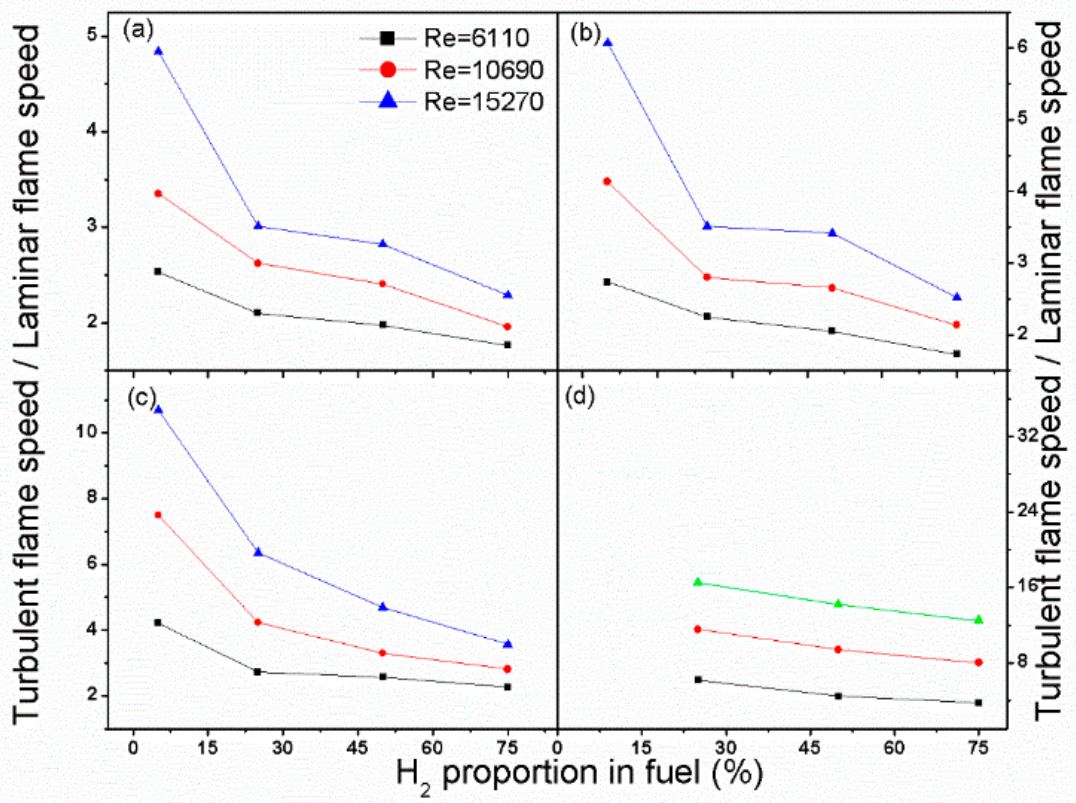

Figure 14. The ratio of turbulent flame velocity to laminar flame speed of the same syngas with different nitrogen dilution rates under different hydrogen proportions in fuel and exit Reynolds numbers: (a) $0 \%$; (b) 10\%; (c) 30\%; (d) 50\% nitrogen dilution volumetric rate.

The effect of nitrogen dilution on the turbulent flame velocity of syngas is shown in Figure 15. Similar to the effect of different hydrogen proportions on the turbulent flame velocity, the variation in the turbulent flame velocity was consistent with that of the laminar flame velocity under different nitrogen dilution ratios. Moreover, at higher dilution, the ratio of the turbulent flame velocity to the laminar flame velocity increased obviously due to the lower laminar flame velocity, as shown in Figure 16. According to scholars, the ratio of the turbulent flame velocity to the laminar flame velocity, and the ratio of the 
turbulent intensity to the laminar flame velocity under lower turbulent intensity, are linear and expressed by the following formula:

$$
S_{T} / S_{L}=1+\mathrm{u}^{\prime} / S_{\mathrm{L}}
$$

where $S_{T}$ stands for turbulent flame velocity, $S_{L}$ stands for laminar flame velocity, and $\mathbf{u}^{\prime}$ represents turbulence intensity. The relationship between the ratio of the turbulent flame velocity to the laminar flame velocity, and the ratio of the outlet flow velocity to the laminar flame velocity, were studied in present work, as shown in Figure 14. It can be seen that there was a strong linear relationship between these two ratios. This was found by fitting the linear relationship, which can be expressed as:

$$
S_{T} / S_{L}=0.96+0.0163 \times U_{0} / S_{L}
$$

According to Formula (3), it was obvious that the fitting formula obtained from the present experiment was in good agreement with Formula (2). Furthermore, it was clearly seen that the turbulent flame velocities of different syngases with different hydrogen proportions and nitrogen dilution ratios was consistent. In addition, as shown in Formula (3), there was a strong linear relationship between the exit velocity and the corresponding turbulent flame velocity, as follows:

$$
\Delta S_{T}=0.0163 \times \Delta U_{0}
$$

Therefore, the exit velocity used in the present work was 40,70, and $100 \mathrm{~m} / \mathrm{s}$ according to the experimental conditions. The exit velocity difference remained at a fixed value of about $30 \mathrm{~m} / \mathrm{s}$, corresponding to the turbulent flame velocity difference of about $50 \mathrm{~cm} / \mathrm{s}$, which is consistent with those shown in Figures 9 and 15. According to Formula (2), the turbulent intensity of the flame front surface in the present experimental system was about 0.016 of the exit velocity, which was very close to the reference value of 0.01 in the literature [19].

According to the definitions of laminar flame velocity and turbulent flame velocity, there was a strong correlation between the wrinkled rate obtained by the flame front length and the ratio of the turbulent flame velocity to the laminar flame velocity, which means $L_{\text {total }} / L_{\text {avg }} \approx A_{\text {total }} / A_{\text {avg }} \approx S_{T} / S_{L}$. Figure 17 shows both ratios for comparison, and the results show that the ratio of the turbulent flame velocity to the laminar flame velocity was generally greater than the wrinkled rate obtained previously, especially for the conditions of lower hydrogen proportion, higher nitrogen dilution rate, and larger Reynolds number. In addition, it was obvious that there was a large error in the structure of the flame front surface obtained from the two-dimensional instantaneous image and the corresponding wrinkled rate, which was smaller than that of the actual flame situation. Furthermore, the ratio of the turbulent flame velocity to the laminar flame velocity was calculated based on the laminar flame velocity under room temperature. However, higher local laminar flame velocity would occur in the turbulent flame under actual operating conditions due to the turbulent effect, which increased the preheating effect. This was consistent with our previous work on syngas [17], which indicated that nitrogen dilution restrained the flame speed of syngas, whereas higher preheat temperature accelerated the flame speed. Through changes in the thickness of the $\mathrm{OH}$ layers and signal intensities, the reaction layer can be compressed by intensifying turbulence and, thereby, the combustion processes of syngas. For these reasons, the ratios in Figure 18 were somewhat higher than those in actual conditions. 


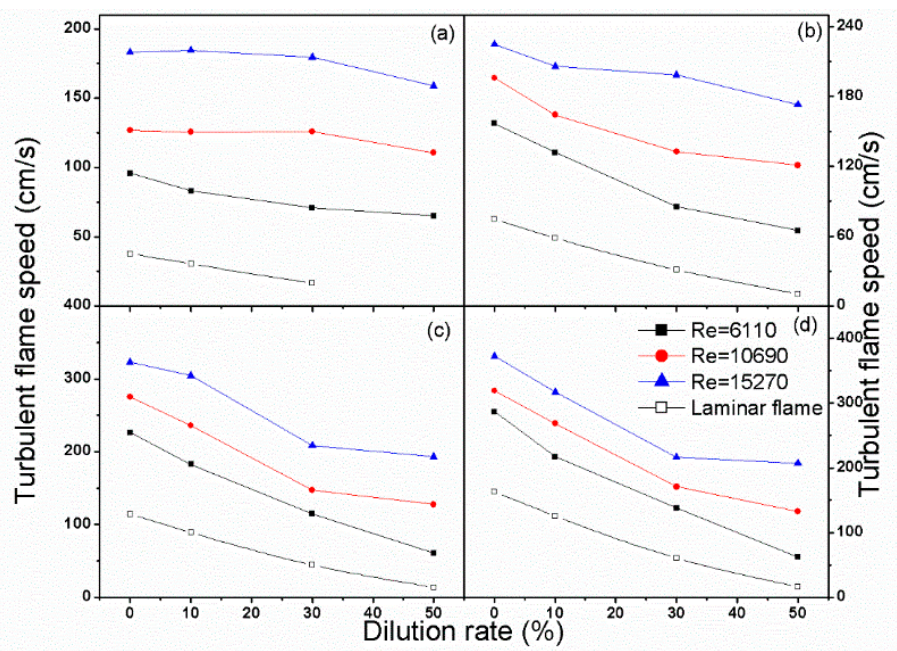

Figure 15. Trend in the turbulent flame velocity of syngas with different hydrogen proportions under different nitrogen dilution rates and exit Reynolds numbers: (a) $5 \%$; (b) $25 \%$; (c) $50 \%$; (d) $75 \%$ hydrogen volumetric proportion.

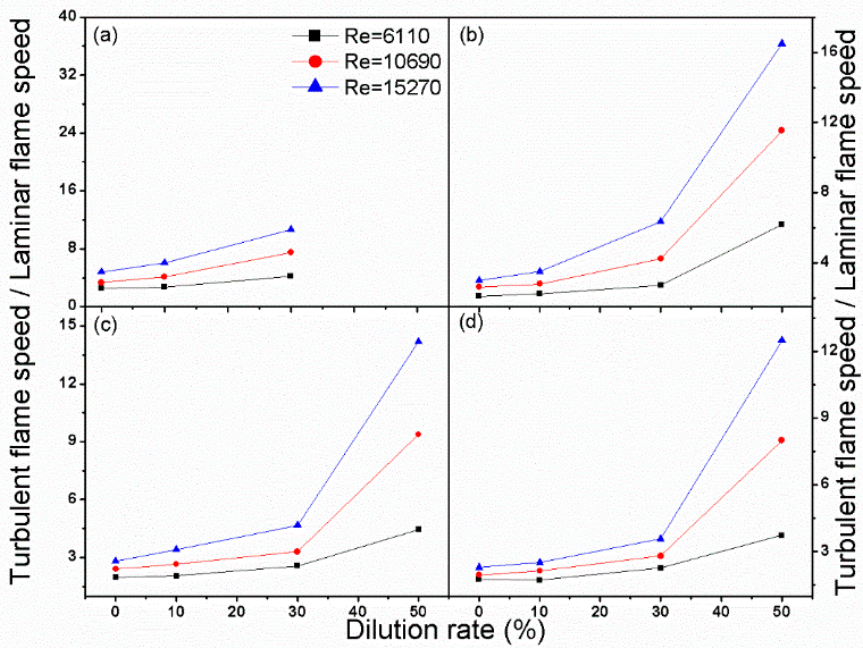

Figure 16. Trend in the ratio of the turbulent flame velocity to the laminar flame speed of the same syngas with different nitrogen dilution rates under different hydrogen proportions and exit Reynolds numbers: (a) $5 \%$; (b) 25\%; (c) 50\%; (d) 75\% hydrogen volumetric proportion.

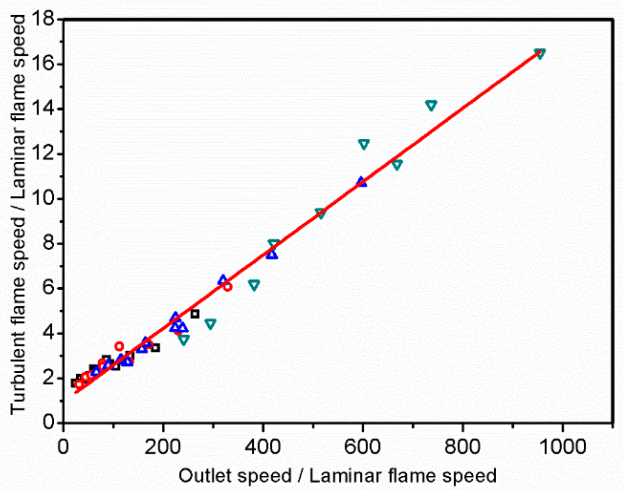

Figure 17. Relationship between the ratio of turbulent flame velocity to laminar flame velocity and the ratio of outlet flow velocity to laminar flame velocity for the same composition of syngas. 

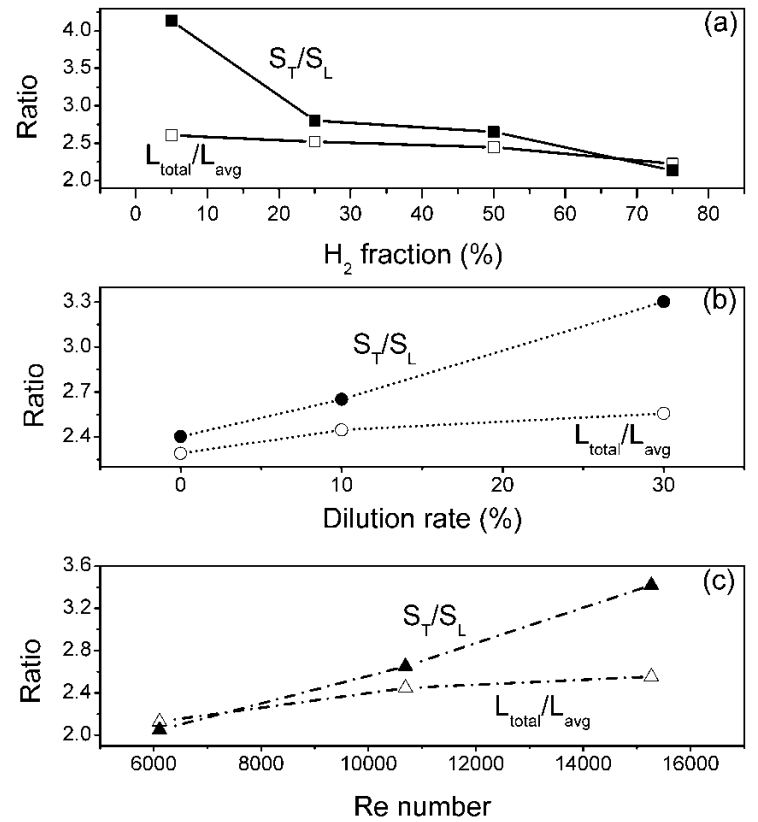

Figure 18. Relationship between the winkled rate and the ratio of turbulent flame velocity to laminar flame velocity under different flame conditions: (a) nitrogen dilution volumetric proportion of $10 \%$, $\operatorname{Re}=10,690$, different hydrogen proportion in fuel; (b) hydrogen volumetric rate of $50 \%, \operatorname{Re}=10,690$, different nitrogen dilution; (c) nitrogen dilution volumetric proportion of $10 \%$, hydrogen volumetric ratio of $50 \%$, different Reynolds number.

\section{Conclusions}

In this paper, the combustion characteristics of a turbulent premixed flame with different proportions of hydrogen and carbon monoxide, and different nitrogen dilution rates and exit Reynolds numbers were investigated. The results showed that the increase in the hydrogen proportion contributed to the formation of the $\mathrm{OH}$ radical in the flame, increased the burning velocity, and decreased the flame size under a certain outlet Reynolds number. As the dilution of syngas increased, the concentration of the $\mathrm{OH}$ radical decreased and the flame size enlarged due to the weakening of combustion intensity. By comparing different Reynolds numbers at the exit, the effect of turbulence intensity on the flame was mainly focused on the structure of the flame front surface. The higher turbulence intensity led to more complicated folds of the flame front surface, which enhanced the combustion intensity. For the same fuel, higher turbulence intensity increased the $\mathrm{OH}$ concentration to some extent and reduced the size of the flame surface.

The instantaneous $\mathrm{OH}$ distribution of the syngas jet flame was obtained by an $\mathrm{OH}-$ PLIF experiment. The flame front surface and the turbulent flame velocities of different syngases under different outlet Reynolds numbers were calculated and analyzed statistically. The results showed that the variation in the turbulent flame velocity of syngas with the hydrogen proportion and nitrogen dilution rate was similar to that of the laminar flame velocity. The higher the hydrogen proportion, the higher the turbulent flame velocity. A higher dilution rate reduced the turbulent flame velocity, and a higher exit Reynolds number increased the turbulent flame velocity. Furthermore, there was a good linear relationship between the turbulent flame velocity and the exit flow velocity of the experimental gas. For each $30 \mathrm{~m} / \mathrm{s}$ increase in the outlet flow velocity, the turbulent flame velocity increased by about $50 \mathrm{~m} / \mathrm{s}$, regardless of its composition. This also indicates that the effect of turbulence intensity on combustion was not affected by the composition of syngas in the range of the present turbulence intensity. 
Author Contributions: Data curation, W.W.; Funding acquisition, L.Y.; Methodology, Y.H.; Project administration, Y.Z.; Supervision, Z.W. and Z.L.; Writing-original draft, W.W.; Writing-review and editing, L.Y. and Y.H. All authors have read and agreed to the published version of the manuscript.

Funding: This research was funded by the National Natural Science Foundation of China [51621005], the Program of Introducing Talents of Discipline to Universities [B08026] and the Key Laboratory for Technology in Rural Water Management of Zhejiang Province, Zhejiang University of Water Resources and Electric Power.

Institutional Review Board Statement: Not applicable.

Informed Consent Statement: Not applicable.

Acknowledgments: The authors would like to thank editor and the reviewers who provided many valuable comments to improve the paper. Li Yang would also like to thank the help of Wubin Weng and the supervisor of Zhihua Wang.

Conflicts of Interest: The authors declare no conflict of interest.

Abbreviations
All the acronyms used in the manuscript are listed as foll
PLIF planar laser-induced fluorescence technology
EGR exhaust gas re-circulation
LCV low calorific value
RS $\quad$ Rayleigh scattering
ICCD
RMS

\section{References}

1. Duwig, C.; Li, B.; Li, Z.; Aldén, M. High resolution imaging of flameless and distributed turbulent combustion. Combust. Flame 2012, 159, 306-316. [CrossRef]

2. Medwell, P.R.; Kalt, P.A.M.; Dally, B.B. Simultaneous imaging of $\mathrm{OH}$, formaldehyde, and temperature of turbulent nonpremixed jet flames in a heated and diluted coflow. Combust. Flame 2007, 148, 48-61. [CrossRef]

3. Kobayashi, H.; Hagiwara, H.; Kaneko, H.; Ogami, Y. Effects of $\mathrm{CO}_{2}$ dilution on turbulent premixed flames at high pressure and high temperature. Proc. Combust. Inst. 2007, 31, 1451-1458. [CrossRef]

4. Zhang, L.; Hui, S.; Yang, Y.; Sun, R.; Ismail, T.M.; El-Salam, M.A.; Ren, X. Numerical and Experimental Assessment of a Novel Multinozzle Burner with $\mathrm{CO}_{2}$ Diluent to Improve the Emissions from a Swirling Flame in a Combustion Chamber. Energy Fuels 2019, 33, 7869-7885. [CrossRef]

5. Nemitallah, M.A.; Rashwan, S.S.; Mansir, I.B.; Abdelhafez, A.A.; Habib, M.A. Review of Novel Combustion Techniques for Clean Power Production in Gas Turbines. Energy Fuels 2018, 32, 979-1004. [CrossRef]

6. Taamallah, S.; Vogiatzaki, K.; Alzahrani, F.M.; Mokheimer, E.M.A.; Habib, M.A.; Ghoniem, A.F. Fuel flexibility, stability and emissions in premixed hydrogen-rich gas turbine combustion: Technology, fundamentals, and numerical simulations. Appl. Energy 2015, 154, 1020-1047. [CrossRef]

7. Wang, Z.; Li, B.; Ehn, A.; Sun, Z.; Li, Z.; Bood, J. Investigation of flue-gas treatment with $\mathrm{O}_{3}$ injection using $\mathrm{NO}$ and $\mathrm{NO}_{2}$ planar laser-induced fluorescence. Fuel 2010, 89, 2346-2352. [CrossRef]

8. Osborne, J.R.; Ramji, S.A.; Carter, C.D.; Peltier, S.; Hammack, S.; Lee, T.; Steinberg, A.M. Simultaneous 10 kHz TPIV, OH PLIF, and $\mathrm{CH}_{2} \mathrm{O}$ PLIF measurements of turbulent flame structure and dynamics. Exp. Fluids 2016, 57, 65. [CrossRef]

9. Elbaz, A.M.; Roberts, W.L. Experimental study of the inverse diffusion flame using high repetition rate OH/acetone PLIF and PIV. Fuel 2016, 165, 447-461. [CrossRef]

10. Johchi, A.; Naka, Y.; Shimura, M.; Tanahashi, M.; Miyauchi, T. Investigation on rapid consumption of fine scale unburned mixture islands in turbulent flame via $10 \mathrm{kHz}$ simultaneous CH-OH PLIF and SPIV. Proc. Combust. Inst. 2015, 3, 3663-3671. [CrossRef]

11. Li, H.; Li, B.; Gao, Q.; Zhang, D.; Li, X.L.Z. Plane laser-Induced fluorescence for flame surface density calculation of OH/CH $\mathrm{O}_{2} \mathrm{O}$ A comparative study. Combust. Sci. Technol. 2018, 24, 523-527.

12. Zhang, M.; Wang, J.; Huang, Z. Turbulent flame structure characteristics of hydrogen enriched natural gas with $\mathrm{CO}_{2}$ dilution. Int. J. Hydrog. Energy 2020, 45, 20426-20435. [CrossRef]

13. Zhang, W.; Wang, J.; Lin, W.; Li, G.; Ye, J.; Guo, S.; Xia, H.; Zhang, M.; Huang, Z. Effects of hydrogen addition on the detailed flame structure of turbulent flames in thin reaction zone. J. Eng. Thermophys. 2021, 42, 795-801.

14. Han, Y.; Cai, G.; Wang, H.; Bruno, R.; Abdelkrim, B. Flow characterization and dilution effects of $\mathrm{N}_{2}$ and $\mathrm{CO}_{2}$ on premixed $\mathrm{CH}_{4}$ /air flames in a swirl-stabilized combustor. Chin. Phys. B 2014, 3, 386-399. 
15. Wang, J.; Matsuno, F.; Okuyama, M.; Ogami, Y.; Kobayashi, H.; Huang, Z. Flame front characteristics of turbulent premixed flames diluted with $\mathrm{CO}_{2}$ and $\mathrm{H}_{2} \mathrm{O}$ at high pressure and high temperature. Proc. Combust. Inst. 2013, 34, 1429-1436. [CrossRef]

16. Yang, L.; Weng, W.; Zhu, Y.; He, Y.; Wang, Z.; Li, Z. Investigation of Dilution Effffect on $\mathrm{CH}_{4} /$ Air Premixed Turbulent Flame Using $\mathrm{OH}$ and $\mathrm{CH}_{2} \mathrm{O}$ Planar Laser-Induced Fluorescence. Energies 2020, 13, 325. [CrossRef]

17. Yang, L.; Wang, Z.; Zhu, Y.; Li, Z.; Zhou, J.; Huang, Z. Premixed jet flame characteristics of syngas using OH planar laser induced fluorescence. Chin. Sci. Bull. 2011, 56, 2862-2868. [CrossRef]

18. Wang, Z.; Weng, W.; He, Y.; $\mathrm{Li}$, Z.; Cen, $\mathrm{K}$. Effect of $\mathrm{H}_{2} / \mathrm{CO}$ ratio and $\mathrm{N}_{2} / \mathrm{CO}_{2}$ dilution rate on laminar burning velocity of syngas investigated by direct measurement and simulation. Fuel 2015, 141, 285-292. [CrossRef]

19. Daniele, S.; Mantzaras, J.; Jansohn, P.; Denisov, A.; Boulouchos, K. Flame front/turbulence interaction for syngas fuels in the thin reaction zones regime: Turbulent and stretched laminar flame speeds at elevated pressures and temperatures. J. Fluid Mech. 2013, 724, 36-68. [CrossRef] 